\title{
The association of waiting times from diagnosis to surgery with survival in women with localised breast cancer in England
}

\author{
M T Redaniel ${ }^{\star, 1}$, R M Martin ${ }^{1}$, S Cawthorn ${ }^{2}$, J Wade ${ }^{1}$ and M Jeffreys ${ }^{1}$ \\ ${ }^{1}$ School of Social and Community Medicine, University of Bristol, Canynge Hall, 39 Whatley Road, Bristol BS8 2PS, UK and \\ ${ }^{2}$ Breast Care Centre, Southmead Hospital, Bristol BS10 5NB, UK
}

Background: Survival from breast cancer in the United Kingdom is lower than in other developed countries. It is unclear to what extent waiting times for curative surgery affect survival.

Methods: Using national databases for England (cancer registries, Hospital Episode Statistics and Office of National Statistics), we identified 53689 women with localised breast cancer, aged $\geqslant 15$ years, diagnosed between 1996 and 2009, who had surgical resection with curative intent within 62 days of diagnosis. We used relative survival and excess risk modelling to determine associations between waiting times and 5-year survival.

Results: The median diagnosis to curative surgery waiting time among breast cancer patients was 22 days (interquartile range (IQR): 15-30). Relative survival was similar among women waiting between 25 and 38 days (RS: 93.5\%; 95\% Cl: 92.8-94.2\%), $<25$ days (RS: 93.0\%; 95\% Cl: 92.5-93.4\%) and between 39 and 62 days (RS: 92.1\%; 95\% Cl: 90.8-93.4\%). There was little evidence of an increase in excess mortality with longer waiting times (excess hazard ratio (EHR): 1.06; 95\% Cl: 0.88-1.27 comparing waiting times 39-62 with 25-38 days). Excess mortality was associated with age (EHR 65-74 vs 15-44 year olds: 1.23; 95\% Cl: 1.07-1.41) and deprivation (EHR most vs least deprived: 1.28; 95\% Cl: 1.09-1.49), but waiting times did not explain these differences.

Conclusion: Within 62 days of diagnosis, decreasing waiting times from diagnosis to surgery had little impact on survival from localised breast cancer.

Systematic efforts to enhance the delivery of cancer services in the United Kingdom have been underway since the publication of the Calman-Hine report in 1995 (Expert Advisory Group on Cancer, 1995). In 1997, $£ 10$ million per year were allocated to improve breast cancer services, with high priority given to reducing waiting times for diagnosis and treatment (Commission for Health Improvement, 2001). The subsequent NHS Cancer Plan (2000) set maximum targets for waiting, including 14 days between GP referral and first hospital appointment, and 31 days between diagnosis and start of treatment (Department of Health, 2000).

Between 1995 and 2007, the 5-year breast cancer survival in the United Kingdom increased by $6.8 \%$, from $74.8 \%$ to $81.6 \%$ (Coleman et al, 2011). During this period, differences in survival between the United Kingdom and countries with the highest 5-year survival decreased from $11.9 \%$ to $7.5 \%$. Nevertheless, survival in the United Kingdom remains lower than in other developed countries (Coleman et al, 2011; Walters et al, 2013), findings that have been attributed to differences in treatment practices, comorbidity and staging procedures (Walters et al, 2013).

Within the United Kingdom, survival differences have been reported between socioeconomic and ethnic groups, as well as between geographical areas. Women living in the most deprived areas had a lower 5-year relative survival compared with those living in the least deprived areas, although these inequalities decreased from 10\% to 6\% between 1973 and 2004 (Lyratzopoulos et al, 2011). Survival was also lower in areas of the North West and London compared with the rest of England (Walters et al, 2011), as well as for women of non-South Asian ethnicity (dos Santos Silva et al, 2003). Delayed diagnosis, poor access to treatment and unhealthy lifestyles are possible reasons for these survival 
inequalities (dos Santos Silva et al, 2003; Rachet et al, 2010; Walters et al, 2011).

The narrowing of survival differences between the United Kingdom and other developed nations could suggest improved breast cancer services, but it could also reflect a ceiling effect whereby survival in other countries has plateaued (Coleman et al, 2011). Nevertheless, survival remains lower in the United Kingdom and survival differences between sociodemographic groups persist in spite of the developments in cancer care. The implementation of the 2-week waiting time standard between GP referral and first hospital appointment did not appear to facilitate early diagnosis and treatment (Robinson et al, 2003; Potter et al, 2007). Paradoxically, there was an increase in waiting times for both patients undergoing routine referral (Potter et al, 2007) and from first hospital appointment to treatment (Robinson et al, 2003).

It is unclear whether delays due to waiting for diagnosis or treatment explain the continued lower comparative survival rates in the United Kingdom because the impact of waiting times on survival is unknown. Using a retrospectively assembled cohort of patients with localised breast cancer, we assessed the association between waiting time from diagnosis to first curative surgery and survival and variations in survival between sociodemographic groups.

\section{MATERIALS AND METHODS}

Data sources. Registration records for breast cancer patients in England were provided by the West Midlands Cancer Intelligence Unit, which is the National Cancer Intelligence Network (NCIN) lead registry for breast cancer in England. The South West Public Health Observatory (SWPHO) linked the cancer registry records to the inpatient Hospital Episode Statistics (HES) and the Office of the National Statistics (ONS) mortality databases and provided the researchers with an anonymised data set. Breast cancer was defined as having a tumour classified in the International Classification of Diseases (ICD) as C50.

From all female breast cancer patients who were identified in the cancer registry, we included women diagnosed between 1 January 1996 and 31 December 2009, who were $\geqslant 15$ years old at the time of diagnosis and who had surgical resection with curative intent. Patients diagnosed with secondary cancers, in situ cancers or diagnosed via death certificates only (DCO) or through autopsy were excluded. We further limited our study to those with localised disease (TNM stage I and II), as described in Figure 1.

From the cancer registry database, a total of 227712 women with breast cancer who satisfied the inclusion criteria, regardless of disease stage, were identified. From these, we excluded those with a waiting time of over 62 days, as they most likely received preoperative therapy or had other conditions necessitating delay $(n=37208)$. A further 1294 women had negative or zero postoperative survival times. Of the remaining women, 53692 (28.3\%) had localised cancers, 5044 (2.7\%) had locally advanced or metastatic disease and 130474 (69\%) did not have information on stage. From the patients with localised disease, only three patients registered from the East Midlands remained in the database. This was verified with the data providers and these women were excluded from the analysis because of suspected data problems. After all exclusions, we were left with 53689 women in the final sample.

Study variables. The waiting time from diagnosis to first curative surgery was defined as the number of days between the date of cancer diagnosis (as recorded in the registry database) and the date of the first curative resection (as recorded in HES). Our starting point was date of diagnosis instead of date of decision to treat (as is used in the National Cancer Waiting Times standards; Department of Health, 2008), because the latter was not available in the cancer

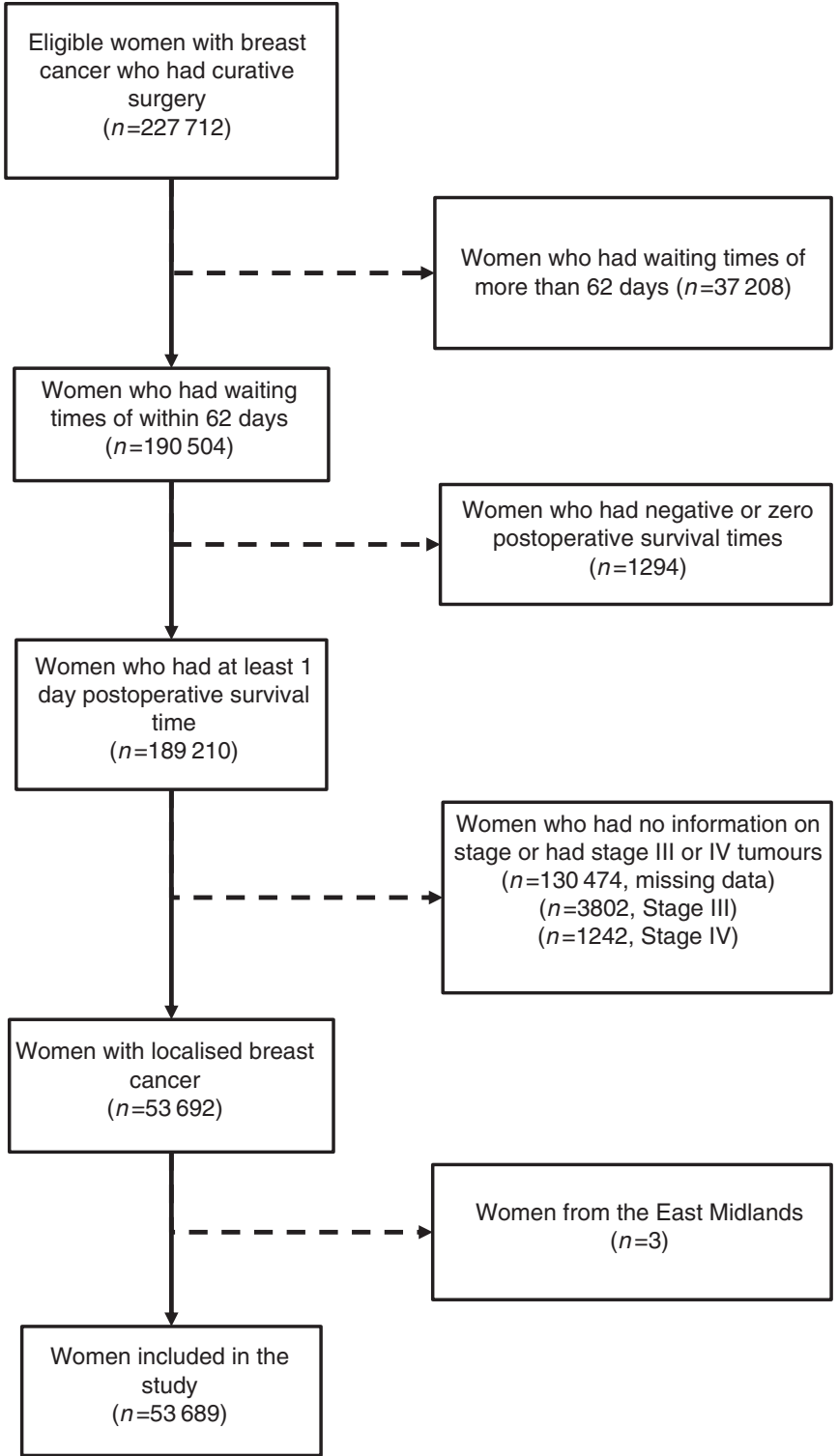

Figure 1. Patient selection flowchart.

registry databases. The difference could be between 1 and 7 days, taking into account the time needed by multidisciplinary teams (MDTs) to plan treatment (NHS Improvement, 2008). Waiting times were categorised into $<25$ days $(n=31959), 25$ to 38 days (reference, $n=16258$ ) and 39 to 62 days $(n=5472)$, so that the middle group was approximately within 1 week of the waiting standard of 31 days.

Curative breast cancer resections were defined as total mastectomy (B27) and breast conserving procedures for cancer (B281-B282) from the Office of Population Censuses and Surveys (OPCS) Classification of Interventions and Procedures (NHS Connecting for Health, 2009). We excluded codes relating to surgical procedures most likely to be used for benign conditions (S Cawthorn, personal communication).

Postoperative survival was defined as the number of days between the date of the first resection and the date of outcome (all-cause death or censoring). As is commonly practiced in population-based cancer survival studies, follow-up was censored at 5 years, or at the end of the study period (31 December 2009), whichever came first.

Other covariables in the study were age, region of residence, ethnicity, stage, grade, histology, period of cancer plan 
implementation and level of deprivation. Age at cancer diagnosis was categorised as $15-44,45-54,55-64,65-74$ and $\geq 75$ years, following age categories used in recent international survival comparisons (Coleman et al, 2011). Geographical region was defined as the patient's region of residence at the time of diagnosis. Ethnicity was self-reported ethnicity, as recorded in the HES database (Department of Health, 2005; Hospital Episode Statistics, 2009). This was categorised as White, Black, Asian, mixed and other ethnic group, and could not be further subdivided because of the small number of cases in ethnic groups other than White. Ethnicity codes were most complete between 2006 and 2008 (SWPHO, personal communication), when the proportion of women with missing data was $<25 \%$. Ethnicity was coded as 'unknown' before 2005. Analyses looking specifically at the effect of ethnicity on waiting times and survival were limited to patients diagnosed between 2005 and 2009. This variable was not included in other multivariable models.

Staging was based on the TNM system (I and II). Grade refers to cell differentiation at the time of tumour biopsy and was classified as well, moderately and poorly differentiated and undifferentiated. Histology was categorised as invasive ductal carcinoma (International Classification of Diseases for Oncology, ICD-O-3, code 8500), invasive lobular carcinoma (8520) and other types (Tavassoli and Devilee, 2003).

The implementation period of the waiting time targets was defined as 'before implementation' (1996-2000), 'initialisation' (2001-2002) and 'implementation' (2003-2009). Level of deprivation was the income component of the 2007 Index of Multiple Deprivation (IMD) (Noble et al, 2008). The IMD score is computed for small geographical areas known as lower super output areas (LSOAs), which have an average population of 1500 people (Communities and Local Government, 2007). Quintiles based on English IMD scores were computed, with the first quintile designated as the least deprived.

Data analysis. The median waiting times by each of the covariables were computed. Using univariable and multivariable linear regression, coefficients reflecting the additional days of waiting for each category compared with the reference category were determined for each covariable. All covariables were controlled for in the multivariable analysis.

Relative survival is a measure of survival, having accounted for mortality because of causes other than cancer. It is the ratio of the observed survival of cancer patients to the probability of survival that would have been expected if patients had had the same survival probability as in the general population (Ederer et al, 1961). Estimates of relative survival were computed using the complete approach (where all women diagnosed between 1996 and 2009 were included, regardless of whether they had full 5-year or partial follow-up) (Brenner et al, 2004). These were expressed as percentages and were computed using the STRS command in STATA, version 12 (StataCorp, 2011). We used age-, sex-, regionand deprivation-specific single-year life tables (Cancer Research UK Cancer Survival Group, 2009) to account for the differences in the underlying mortality. We used the life table for 2005 for the years 2006-2009. We do not anticipate any significant differences in life expectancies for the more recent years and any bias in our estimates are expected to be small. We used the Ederer II method (Ederer et al, 1961) to determine expected survival.

To determine the association of waiting times with mortality, excess hazards ratios (EHRs) at 5 years were computed using a generalised linear model with a Poisson error structure (Dickman et al, 2004). The EHR is the ratio of mortality rates in the presence of one factor and the mortality rates in the absence of the same factor, once the reference population mortality is taken into account (Dickman et al, 2004). It can be interpreted as equivalent to the risk ratio and used to quantify the association between cancer survival and the waiting time between diagnosis and curative surgery. The EHR is calculated from excess mortality modelling, a multivariable extension of relative survival, while controlling for the effects of other covariables. First, each variable was added individually to determine their effect on the association of waiting times with survival. A full model with all the variables added simultaneously was built to determine the association of waiting time with survival, controlling for the effect of all the covariates. We used the likelihood ratio test to determine goodness of fit. We also tested for evidence of an interaction between waiting time categories and follow-up (where follow-up is a binary variable coded as 1 = first year of follow-up and $2=$ second to fifth years).

Because of the limitations of data for ethnicity before 2005, we did not include this variable in our multivariable excess mortality models. We conducted a sensitivity analysis to determine whether ethnicity is a confounder of the association between waiting time and survival using data from patients diagnosed between 2005 and 2009. We found no difference in the EHRs between age-adjusted models and models controlling for ethnicity (data not shown).

To determine whether waiting times explained associations of age and ethnic groups, region of residence and deprivation quintile with excess mortality, the EHRs from multivariable models (controlled for all other covariables) were compared with models without waiting times. Any differences in estimates were noted and attributed to the effect of adjustment for waiting times.

We used multiple imputation using chained equations (ICEs) to account for missing data on grade, morphology and deprivation quintile (Table 1; Royston, 2005; Nur et al, 2010). Imputation models were derived for each missing variable and included: the exposure of interest (diagnosis to first curative surgery waiting time); the incomplete variables; all other covariables; and outcome (postoperative survival time and outcome (dead or censored)). A total of 20 complete data sets were constructed to reduce sampling variability from the imputation process (Sterne et al, 2009) and the results were combined using Rubin's Rules (Royston, 2005; Nur et al, 2010). The distributions of the imputed variables were similar to the distributions of the measured variables. All regression analyses were based on the imputed data set.

\section{RESULTS}

Descriptive analysis. Overall, our sample had a median diagnosis to curative surgery waiting time of 22 days (interquartile range (IQR): 15-30). The distribution of the patients, the median waiting time between diagnosis and curative surgery and the number of additional days' waiting across the levels of different sociodemographic and clinical variables are shown in Table 1 . Women $\geqslant 75$ years old had waiting times 2 days longer than those aged 15-44 years (coefficient (Coef): 2.21; 95\% confidence interval (95\% CI): 1.38-3.04). Women living outside of London, with the exception of the South East, had between 2 and 8 days shorter waiting times. Women with undifferentiated tumours were waiting 8 days longer compared with those with well-differentiated tumours (Coef: 8.82; 95\% CI: 4.66-12.98). Waiting times increased by 3 days after the plan was fully implemented (Coef: 3.31; 95\% CI: $2.40-4.21)$. There were no differences in waiting times by stage, histology and deprivation quintile.

Survival analysis. The 5-year relative survival for the total study sample was $93.0 \%$ (95\% CI: 92.7-93.4\%). Relative survival estimates did not differ by waiting time categories. Relative survival was similar among women waiting between 25 and 38 days (RS: 93.5\%; 95\% CI: 92.8-94.2\%), <25 days (RS: 93.0\%; 95\% CI: 92.5-93.4\%) and between 39 and 62 days (RS: 92.1\%; 95\% CI: 90.8-93.4\%). Relative survival slightly increased for each period, from $90.9 \%(95 \%$ CI: $90.2-91.7 \%)$ in the period before 
Table 1. The distribution and association of selected risk factors with waiting times from diagnostic to curative surgery, localised breast cancer, 19962009

\section{Waiting times (days) Univariable analysis $\quad$ Multivariable analysis ${ }^{\mathrm{a}}$}

\begin{tabular}{|c|c|c|c|c|c|c|c|c|}
\hline Variable & $\mathbf{N}$ & $\%$ & Median & IQR & Coef ${ }^{b}$ & $\begin{array}{l}95 \% \text { Confidence } \\
\text { interval }\end{array}$ & Coef ${ }^{b}$ & $\begin{array}{c}95 \% \text { Confidence } \\
\text { interval }\end{array}$ \\
\hline \multicolumn{9}{|c|}{ Age group } \\
\hline $15-44$ & 6216 & 11.58 & 20 & $(14-29)$ & 0.00 & & 0.00 & \\
\hline $45-54$ & 12827 & 23.89 & 21 & (14-29) & 0.48 & -0.52 to 1.48 & 0.28 & -0.53 to 1.09 \\
\hline $55-64$ & 15527 & 28.92 & 22 & $(15-30)$ & 0.92 & -1.07 to 2.92 & 0.38 & -1.28 to 2.03 \\
\hline $65-74$ & 11953 & 22.26 & 22 & (15-30) & 1.31 & 0.06 to 2.55 & 0.72 & -0.25 to 1.69 \\
\hline$\geqslant 75$ & 7166 & 13.35 & 23 & $(16-32)$ & 2.90 & 1.86 to 3.94 & 2.21 & 1.38 to 3.04 \\
\hline
\end{tabular}

Region of residence

\begin{tabular}{|c|c|c|c|c|c|c|c|c|}
\hline London & 723 & 1.35 & 27 & $(19-35)$ & 0.00 & & & \\
\hline North East & 10990 & 20.47 & 19 & $(13-27)$ & -6.94 & -9.40 to -4.48 & -7.48 & -8.98 to -5.98 \\
\hline North West & 2428 & 4.52 & 16 & $(11-26)$ & -8.41 & -10.75 to -6.06 & -8.60 & -10.10 to -7.10 \\
\hline Yorkshire and the Humber & 17052 & 31.76 & 22 & $(15-29)$ & -4.74 & -7.11 to -2.38 & -5.20 & -6.72 to -3.68 \\
\hline West Midlands & 3607 & 6.72 & 19 & $(13-26)$ & -7.13 & -9.47 to -4.80 & -7.60 & -9.10 to -6.11 \\
\hline East of England & 15672 & 29.19 & 25 & $(18-33)$ & -1.19 & -4.21 to 1.83 & -2.00 & -3.76 to -0.25 \\
\hline South East & 1863 & 3.47 & 24 & $(16-34)$ & -1.90 & -6.86 to 3.07 & -1.69 & -6.53 to 3.14 \\
\hline South West & 1354 & 2.52 & 21 & $(13-31)$ & -4.53 & -6.87 to -2.20 & -4.26 & -5.76 to -2.76 \\
\hline
\end{tabular}

Ethnicity, major groups ${ }^{c}$

\begin{tabular}{|c|c|c|c|c|c|c|c|c|}
\hline White & 18800 & 74.23 & 23 & $(16-31)$ & 0.00 & & & \\
\hline Black & 133 & 0.53 & 27 & $(21-36)$ & 3.79 & 1.01 to 6.58 & 2.79 & 0.88 to 4.69 \\
\hline Asian & 267 & 1.05 & 22 & $(16-31)$ & 0.26 & -1.16 to 1.69 & 0.22 & -1.68 to 2.12 \\
\hline Mixed & 45 & 0.18 & 27 & $(20-33)$ & 1.20 & -1.01 to 3.41 & 0.33 & -2.29 to 2.95 \\
\hline Other ethnic group & 83 & 0.33 & 25 & $(19-32)$ & 1.34 & -0.46 to 3.14 & 0.10 & -1.77 to 1.98 \\
\hline Unknown & 5997 & 23.68 & 25 & $(19-33)$ & 1.83 & 0.87 to 2.79 & 1.49 & 0.28 to 2.71 \\
\hline
\end{tabular}

\section{Stage}

\begin{tabular}{|l|l}
\hline I & 24724 \\
\hline
\end{tabular}

II

46.05

53.95

22
22

$(15-30)$
$(15-29)$

0.00

-1.22 to 0.32

$-0.16$

-0.61 to 0.29

\section{Histology}

Invasive lobular carcinoma

Other

Not otherwise specified

\begin{tabular}{c|c|c}
41291 & 76.91 & 22 \\
5654 & 10.53 & 22 \\
6720 & 12.52 & 22 \\
24 & 0.04 & 18
\end{tabular}

\begin{tabular}{l|}
22 \\
22 \\
22
\end{tabular}

$(15-29)$
$(15-31)$
$(15-30)$

0.00

$(15-30)$
$(11-32)$

1.13

0.77

0.63 to 1.63

0.26 to 1.28

0.91

0.54

0.48 to 1.33

0.27 to 0.80

\section{Grade (degree of differentiation)}

\begin{tabular}{|c|c|c|c|c|c|c|c|c|}
\hline Well differentiated & 10081 & 18.78 & 22 & $(15-30)$ & 0.00 & & & \\
\hline Moderately differentiated & 25096 & 46.74 & 22 & $(15-30)$ & 0.09 & -0.71 to 0.90 & -0.26 & -1.06 to 0.54 \\
\hline Poorly differentiated & 16843 & 31.37 & 21 & $(15-29)$ & -0.67 & -2.07 to 0.73 & -0.78 & -1.97 to 0.41 \\
\hline Undifferentiated & 15 & 0.03 & 27 & $(26-46)$ & 8.84 & 5.03 to 12.65 & 8.82 & 4.66 to 12.98 \\
\hline Unknown & 1654 & 3.08 & 21 & (14-29) & & & & \\
\hline \multicolumn{9}{|l|}{ Deprivation quintile } \\
\hline 1, Least deprived & 10333 & 19.25 & 22 & $(15-30)$ & 0.00 & & & \\
\hline 2 & 11694 & 21.78 & 22 & $(15-30)$ & 0.18 & -0.20 to 0.56 & 0.00 & -0.46 to 0.47 \\
\hline 3 & 10949 & 20.39 & 22 & $(15-30)$ & 0.37 & -0.21 to 0.95 & 0.17 & -0.62 to 0.96 \\
\hline 4 & 9526 & 17.74 & 22 & $(15-29)$ & -0.10 & -1.09 to 0.90 & 0.28 & -0.55 to 1.11 \\
\hline 5, Most deprived & 7857 & 14.63 & 21 & $(15-29)$ & -0.52 & -2.58 to 1.54 & 0.68 & -0.44 to 1.80 \\
\hline Unknown & 3330 & 6.20 & 19 & $(12-28)$ & & & & \\
\hline \multicolumn{9}{|c|}{ Cancer plan implementation period } \\
\hline $\begin{array}{l}\text { Before implementation } \\
(1996-2000)\end{array}$ & 10461 & 19.48 & 19 & $(13-27)$ & 0.00 & & & \\
\hline Initialisation (2001-2002) & 8169 & 15.22 & 20 & $(14-28)$ & 1.10 & 0.39 to 1.81 & 0.95 & 0.37 to 1.54 \\
\hline $\begin{array}{l}\text { Implementation } \\
(2003-2009)\end{array}$ & 35059 & 65.30 & 23 & $(16-31)$ & 3.65 & 1.66 to 5.64 & 3.31 & 2.40 to 4.21 \\
\hline \multirow{3}{*}{\multicolumn{9}{|c|}{$\begin{array}{l}\text { Abbreviations: Coef = coefficient; } I Q R=\text { interquartile range. } \\
\text { a Adjusted for all the other variables in the table except ethnicity. } \\
{ }^{b} \text { Coefficient - represents the additional days waiting for each category compared with the reference category. }\end{array}$}} \\
\hline & & & & & & & & \\
\hline & & & & & & & & \\
\hline \multicolumn{9}{|c|}{ cAll codes before 2005 were recoded as unknown; represents only data from 2005 to 2009.} \\
\hline
\end{tabular}


Table 2. The association of waiting times from diagnosis to first curative surgery with excess mortality (at 5 years post surgery) among women with localised breast cancer

\begin{tabular}{|c|c|c|c|c|c|}
\hline \multirow[b]{3}{*}{ Model } & \multicolumn{5}{|c|}{ Waiting times } \\
\hline & \multicolumn{2}{|c|}{$<25$ days } & \multirow{2}{*}{$\begin{array}{c}25-38 \text { days } \\
\begin{array}{c}\text { Excess hazards } \\
\text { ratio }\end{array}\end{array}$} & \multicolumn{2}{|c|}{ 39-62 days } \\
\hline & $\begin{array}{l}\text { Excess hazards } \\
\text { ratio }\end{array}$ & $\begin{array}{l}\text { 95\% Confidence } \\
\text { interval }\end{array}$ & & $\begin{array}{l}\text { Excess hazards } \\
\text { ratio }\end{array}$ & $\begin{array}{l}\text { 95\% Confidence } \\
\text { interval }\end{array}$ \\
\hline Crude model & 1.10 & 0.99 to 1.23 & 1.00 & 1.06 & 0.88 to 1.27 \\
\hline Age-adjusted & 1.09 & 0.98 to 1.22 & 1.00 & 1.05 & 0.87 to 1.27 \\
\hline $\begin{array}{l}\text { Age-adjusted + region of } \\
\text { residence }\end{array}$ & 1.05 & 0.94 to 1.17 & 1.00 & 1.05 & 0.88 to 1.27 \\
\hline Age-adjusted + stage & 1.05 & 0.94 to 1.16 & 1.00 & 1.11 & 0.93 to 1.32 \\
\hline Age-adjusted + histology & 1.09 & 0.98 to 1.21 & 1.00 & 1.08 & 0.90 to 1.30 \\
\hline Age-adjusted + grade & 1.03 & 0.93 to 1.14 & 1.00 & 1.11 & 0.93 to 1.31 \\
\hline $\begin{array}{l}\text { Age-adjusted + deprivation } \\
\text { quintile }\end{array}$ & 1.09 & 0.98 to 1.21 & 1.00 & 1.05 & 0.87 to 1.26 \\
\hline Age-adjusted + period $^{\text {a }}$ & 1.05 & 0.94 to 1.17 & 1.00 & 1.03 & 0.86 to 1.24 \\
\hline Age-adjusted + all covariates & 0.93 & 0.84 to 1.03 & 1.00 & 1.09 & 0.93 to 1.29 \\
\hline
\end{tabular}

implementation to $92.2 \%$ (95\% CI: $91.4-93.0 \%)$ during the initiation phase and $94.4 \%$ (95\%CI: $93.9-94.9 \%)$ in the implementation stage.

In comparison with patients with waiting times of 25 to 38 days (reference), patients waiting for $<25$ days had a $10 \%$ higher excess mortality (EHR: 1.10; 95\% CI: 0.99-1.23; Table 2). However, this effect was reversed after adjusting for all covariables (EHR: 0.93; 95\% CI: 0.84-1.03). For patients with waiting times of 39 to 62 days, we found no evidence of a higher excess mortality when compared with the reference group (EHR: 1.06; 95\% CI: 0.88-1.27). After adjustment for all covariables simultaneously, there was little evidence of higher excess mortality for people waiting for 39 to 62 days (EHR: 1.09; 95\% CI: 0.93-1.29). There was also no evidence of an interaction between waiting time and follow-up $(P$-value $=0.8)$.

Adjusting for waiting times did not attenuate associations of age or deprivation with survival. After controlling for all variables, including waiting times, there was strong evidence of a $23 \%$ higher excess mortality (95\% CI: 1.07-1.41) among women in the 65-74 age group compared with those aged 15-44 years (Table 3 ). There were generally small differences across regions, although following adjustment for all covariables, women residing in the North West had a $40 \%$ (95\% CI: 1.00-1.97) higher excess mortality as compared with London residents. Women from the most deprived neighbourhoods had a $28 \%$ higher excess mortality (95\% CI: 1.09-1.49) compared with the least deprived neighbourhoods. There was inconclusive evidence of variations in survival by ethnicity.

\section{DISCUSSION}

Among women with localised breast cancer undergoing surgical resection with curative intent, we found little evidence of an increase in excess mortality with longer waiting times, within a waiting time period of up to 62 days of diagnosis. We confirmed previous observations of lower survival at older ages, in certain geographic regions and in deprived areas. However, waiting times did not explain these sociodemographic associations.

Our study is one of the few that have looked at the effect of waiting times on breast cancer survival. However, it is not without limitations. We used routinely collected data from cancer registries and HES in England, which is known to be of high completeness and low percentage of death certificate-only cases (Office of National Statistics, 2011), but does not contain all information pertinent to patient care. For example, we do not have data on comorbidities and functional state at the time of diagnosis, which could have explained the timeliness of treatment. These data were not available from our data set. To control for disease severity, we adjusted for stage and tumour differentiation. As only Cancer registry-HES inpatient data could be provided, we also do not have information on other forms of treatment. To take these into account, we have restricted our analysis to early-stage cancers, which would most likely have received surgery as the first form of treatment (National Collaborating Centre for Cancer, 2009). Nevertheless, we expect women with locally advanced and metastatic tumours to have worse survival than our cohort (Rutherford et al, 2013; Walters et al, 2013).

Our study could be subject to selection bias, as $69 \%$ of registered breast cancer cases did not have information on stage. Nevertheless, the distribution of cases with known stage was similar to those in published literature (Walters et al, 2013), which suggests that the bias is nondifferential. Our relative survival estimates are in line with published literature (Rutherford et al, 2013).

In the estimation of relative survival, we have used the Ederer II method. In this approach, the survival proportions are based on women alive at the start of each interval and are dependent on observed mortality of the preceding intervals. This could underestimate survival if the study population has high fatality in earlier intervals, such as in the case of the elderly or those with comorbidities. We have adjusted for age in the analysis to minimise this bias.

We used the complete approach for all analyses for consistency, but have performed sensitivity analyses using period analysis (Brenner et al, 2004). In contrast to the complete approach, period analysis only takes into account the survival experience of women for a particular period, such as in the years 2005-2009. The relative survival estimates and EHRs using the complete approach were very similar to the estimates obtained using the period approach. The survival differences between the categories of the exposure variables did not change when different approaches were used (data not shown). 
Table 3. The association of sociodemographic factors with excess mortality at 5 years post surgery

\begin{tabular}{|c|c|c|c|c|c|c|c|c|}
\hline & \multicolumn{2}{|c|}{ Crude model } & \multicolumn{2}{|c|}{ Age-adjusted model } & \multicolumn{2}{|c|}{ Covariate-adjusted model ${ }^{a}$} & \multicolumn{2}{|c|}{$\begin{array}{l}\text { Waiting time }+ \text { covariate } \\
\text { adjusted }\end{array}$} \\
\hline Variable & $\begin{array}{c}\text { Excess } \\
\text { hazards } \\
\text { ratio }\end{array}$ & $\begin{array}{c}95 \% \\
\text { Confidence } \\
\text { interval }\end{array}$ & $\begin{array}{c}\text { Excess } \\
\text { hazards } \\
\text { ratio }\end{array}$ & $\begin{array}{c}95 \% \\
\text { Confidence } \\
\text { interval }\end{array}$ & $\begin{array}{c}\text { Excess } \\
\text { hazards } \\
\text { ratio }\end{array}$ & $\begin{array}{c}95 \% \\
\text { Confidence } \\
\text { interval }\end{array}$ & $\begin{array}{c}\text { Excess } \\
\text { hazards } \\
\text { ratio }\end{array}$ & $\begin{array}{c}95 \% \\
\text { Confidence } \\
\text { interval }\end{array}$ \\
\hline \multicolumn{9}{|l|}{ Age group } \\
\hline $\begin{array}{l}15-44 \\
45-54 \\
55-64 \\
65-74 \\
\geqslant 75\end{array}$ & $\begin{array}{l}1.00 \\
0.71 \\
0.66 \\
0.73 \\
0.42\end{array}$ & $\begin{array}{l}0.62 \text { to } 0.80 \\
0.58 \text { to } 0.75 \\
0.62 \text { to } 0.84 \\
0.29 \text { to } 0.61\end{array}$ & & & $\begin{array}{l}1.00 \\
1.00 \\
1.10 \\
1.24 \\
0.99\end{array}$ & $\begin{array}{l}0.88 \text { to } 1.13 \\
0.97 \text { to } 1.24 \\
1.08 \text { to } 1.42 \\
0.80 \text { to } 1.22\end{array}$ & $\begin{array}{l}1.00 \\
1.00 \\
1.10 \\
1.23 \\
0.99\end{array}$ & $\begin{array}{l}0.88 \text { to } 1.13 \\
0.97 \text { to } 1.24 \\
1.07 \text { to } 1.41 \\
0.80 \text { to } 1.22\end{array}$ \\
\hline \multicolumn{9}{|c|}{ Ethnicity, major groups ${ }^{b}$} \\
\hline $\begin{array}{l}\text { White } \\
\text { Black } \\
\text { Asian } \\
\text { Mixed } \\
\text { Unknown }\end{array}$ & $\begin{array}{l}1.00 \\
1.31 \\
1.19 \\
0.63 \\
0.15\end{array}$ & $\begin{array}{l}0.34 \text { to } 5.09 \\
0.50 \text { to } 2.82 \\
0.06 \text { to } 6.88 \\
0.05 \text { to } 0.45\end{array}$ & $\begin{array}{l}1.00 \\
1.26 \\
1.16 \\
0.63 \\
0.16\end{array}$ & $\begin{array}{l}0.31 \text { to } 5.02 \\
0.49 \text { to } 2.77 \\
0.05 \text { to } 7.32 \\
0.06 \text { to } 0.45\end{array}$ & $\begin{array}{l}1.00 \\
0.90 \\
0.81 \\
0.43 \\
0.32\end{array}$ & $\begin{array}{l}0.22 \text { to } 3.67 \\
0.31 \text { to } 2.07 \\
0.02 \text { to } 7.69 \\
0.17 \text { to } 0.60\end{array}$ & $\begin{array}{l}1.00 \\
0.91 \\
0.80 \\
0.39 \\
0.31\end{array}$ & $\begin{array}{l}0.23 \text { to } 3.55 \\
0.31 \text { to } 2.06 \\
0.02 \text { to } 9.16 \\
0.17 \text { to } 0.59\end{array}$ \\
\hline \multicolumn{9}{|c|}{ Region of residence } \\
\hline $\begin{array}{l}\text { London } \\
\text { North East } \\
\text { North West } \\
\text { Yorkshire and } \\
\text { the Humber } \\
\text { West } \\
\text { Midlands } \\
\text { East of } \\
\text { England } \\
\text { South East } \\
\text { South West }\end{array}$ & $\begin{array}{l}1.00 \\
0.86 \\
1.15 \\
0.85 \\
0.79 \\
\\
\\
0.63 \\
\\
0.89 \\
0.84\end{array}$ & $\begin{array}{l}0.62 \text { to } 1.20 \\
0.81 \text { to } 1.65 \\
0.61 \text { to } 1.17 \\
0.56 \text { to } 1.13 \\
0.45 \text { to } 0.88 \\
0.61 \text { to } 1.29 \\
0.57 \text { to } 1.25\end{array}$ & $\begin{array}{l}1.00 \\
0.87 \\
1.16 \\
0.86 \\
\\
0.79 \\
\\
0.65 \\
\\
\\
0.90 \\
0.86\end{array}$ & $\begin{array}{l}0.62 \text { to } 1.21 \\
0.81 \text { to } 1.66 \\
0.62 \text { to } 1.19 \\
0.55 \text { to } 1.14 \\
0.46 \text { to } 0.90 \\
0.61 \text { to } 1.32 \\
0.57 \text { to } 1.28\end{array}$ & $\begin{array}{l}1.00 \\
0.96 \\
1.36 \\
1.07 \\
\\
0.95 \\
\\
0.91 \\
\\
\\
0.96 \\
0.92\end{array}$ & $\begin{array}{l}0.70 \text { to } 1.30 \\
0.97 \text { to } 1.92 \\
0.79 \text { to } 1.45 \\
0.68 \text { to } 1.33 \\
0.66 \text { to } 1.25 \\
0.67 \text { to } 1.37 \\
0.63 \text { to } 1.34\end{array}$ & $\begin{array}{l}1.00 \\
0.99 \\
1.40 \\
1.09 \\
\\
0.98 \\
\\
\\
0.92 \\
\\
\\
0.96 \\
0.94\end{array}$ & $\begin{array}{l}0.72 \text { to } 1.35 \\
1.00 \text { to } 1.97 \\
0.80 \text { to } 1.48 \\
0.70 \text { to } 1.37 \\
0.67 \text { to } 1.25 \\
0.67 \text { to } 1.38 \\
0.65 \text { to } 1.37\end{array}$ \\
\hline \multicolumn{9}{|c|}{ Deprivation quintile $^{c}$} \\
\hline $\begin{array}{l}\text { 1, Least } \\
\text { deprived } \\
2 \\
3 \\
4 \\
5, \text { Most } \\
\text { deprived }\end{array}$ & $\begin{array}{l}1.00 \\
\\
1.03 \\
1.11 \\
1.25 \\
1.36\end{array}$ & $\begin{array}{l}0.89 \text { to } 1.20 \\
0.96 \text { to } 1.28 \\
1.07 \text { to } 1.45 \\
1.16 \text { to } 1.60\end{array}$ & $\begin{array}{l}1.00 \\
\\
1.04 \\
1.12 \\
1.26 \\
1.34\end{array}$ & $\begin{array}{l}0.89 \text { to } 1.21 \\
0.96 \text { to } 1.29 \\
1.08 \text { to } 1.47 \\
1.14 \text { to } 1.58\end{array}$ & $\begin{array}{l}1.00 \\
\\
1.10 \\
1.16 \\
1.23 \\
1.28\end{array}$ & $\begin{array}{l}0.96 \text { to } 1.27 \\
1.01 \text { to } 1.34 \\
1.06 \text { to } 1.42 \\
1.09 \text { to } 1.49\end{array}$ & $\begin{array}{l}1.00 \\
\\
1.10 \\
1.16 \\
1.23 \\
1.28\end{array}$ & $\begin{array}{l}0.96 \text { to } 1.28 \\
1.01 \text { to } 1.34 \\
1.07 \text { to } 1.43 \\
1.09 \text { to } 1.49\end{array}$ \\
\hline
\end{tabular}

The waiting time targets were implemented to facilitate access to cancer care, but evidence of a beneficial impact on breast cancer survival remains inadequate. Although advanced stage at disease presentation is associated with decreased survival (Richards et al, 1999; Sant et al, 2003), our results do not provide evidence to suggest that among women with TNM stage I and II, waiting up to 62 days resulted in a degree of disease progression that affected survival. However, the disease treatment process is complex. Patients with more severe disease manifestations or advanced stage at diagnosis could have been expedited through the process (Bilimoria et al, 2011). More research is needed to explore these determinants of waiting times, to see if they affect breast cancer survival.

Our results show that older age and region of residence were strong predictors of both waiting times and survival. Compared with the younger age groups, higher excess mortality among women aged 65-74 years could reflect clinical management practices. The odds of nonstandard management, including not receiving primary surgery, not undergoing axillary node surgery, not undergoing tests for steroid receptors and not receiving radiotherapy following breast-conserving surgery have been shown to increase with age, notwithstanding tumour characteristics (Lavelle et al, 2007). There is also a reluctance to offer chemotherapy to older women (Ring et al, 2013) and they are also less likely to undergo breast-conserving surgery (Raine et al, 2010). Factors contributing to the use of nonstandard therapy include the clinicians' perceived small benefit of standard therapy, frailty and comorbidities (Biganzoli et al, 2012; Ring et al, 2013).

Elderly patients need complex preoperative management (Bilimoria et al, 2011) and this could have explained longer waiting times for women aged $\geqslant 75$ years. They were also more likely to be 
admitted as emergencies, indicating more severe disease at presentation (Raine et al, 2010). Compared with all other age groups, the proportion of women with missing staging information was higher among those aged $\geqslant 75$ years. These missing data could have resulted in an underrepresentation of these women in our sample and an overestimation of the relative survival. This could have been the reason for the lower excess mortality in this age group.

Survival differences by geographical areas could likewise be indicative of inequalities in access to cancer care. Geographical variation in survival have been previously documented (Walters et al, 2011) and could be due to differential access to treatment facilities. Access rates for radiotherapy ranged from $25.2 \%$ and 27.7\% in the Yorkshire and the Humber region and in the North East of England, respectively, to $49.0 \%$ in the East of England (Williams and Drinkwater, 2009). Nevertheless, in our study, there is an overrepresentation of women from the North East, Yorkshire and the Humber and the East of England where staging information is available for $>75.0 \%$ of registered cases. The survival of women in other regions could have been overestimated if missingness is related to older age and poor prognosis. However, our data suggest this might only be true for the West Midlands and Yorkshire and the Humber. More research is needed to ascertain reasons for these observed inequalities.

Although deprivation was a predictor of survival, it had no effect on waiting times. This implies that once a patient is diagnosed with breast cancer, the length of time they spend in the health-care system is not related to their deprivation level. The reasons for lower survival among more deprived groups may depend on factors before their entry into the system. Patients in the most deprived group were more likely to present as emergency cases (Raine et al, 2010), which could be indicative of more advanced disease at presentation. Nevertheless, those in the most deprived groups were reported to be less likely to receive preferred procedures, such as breast-conserving surgery cancer, than affluent patients (Raine et al, 2010). Survival inequalities between geographical areas and deprivation groups decreased throughout the years of our study (Lyratzopoulos et al, 2011; Walters et al, 2011), but the effects of developments in cancer care to these improvements remain unclear.

Our study shows that, within a waiting time period of up to 62 days of diagnosis, waiting times were not strongly related to survival from localised breast cancer. More research is needed to fully understand the role of clinical practices, and access to and/or utilisation of cancer care services in order to improve breast cancer survival and decrease survival differences by sociodemographic groups.

\section{ETHICS APPROVAL}

This project was approved by the Faculty of Medicine and Dentistry Committee for Ethics (FCE), University of Bristol (101153) and by the NHS South Central-Berkshire B Research Ethics Board (11/SC/0387). Use of cancer registry data was approved by the National Information Governance Board (NIGB, ECC 7-02(d)/2011).

\section{ACKNOWLEDGEMENTS}

Cancer registry-HES-ONS linked data were provided by the West Midlands Cancer Intelligence Unit (WMCIU) and the South West Public Health Observatory (SWPHO). We thank Jasmin Sidhu (WMCIU) and Luke Hounsome (SWPHO) for their assistance. We also thank Dr Paul Dickman (Karolinska Institutet), Dr Paul Lambert (University of Leicester) and Dr UIa Nur (London School of Hygiene and Tropical Medicine) for their invaluable advice in the data analysis. This study is funded by Cancer Research UK (Grant Ref: C41354/A13273).

\section{DISCLAIMER}

The funding agency had no role in the study design, collection, analysis and interpretation of data, writing of the report and the decision to submit the article for publication.

\section{REFERENCES}

Biganzoli L, Wildiers H, Oakman C, Marotti L, Loibl S, Kunkler I, Reed M, Ciatto S, Voogd AC, Brain E, Cutuli B, Terret C, Gosney M, Aapro M, Audisio R (2012) Management of elderly patients with breast cancer: updated recommendations of the International Society of Geriatric Oncology (SIOG) and European Society of Breast Cancer Specialists (EUSOMA). Lancet Oncol 13(4): e148-e160.

Bilimoria KY, Ko CY, Tomlinson JS, Stewart AK, Talamonti MS, Hynes DL, Winchester DP, Bentrem DJ (2011) Wait times for cancer surgery in the United States: trends and predictors of delays. Ann Surg 253(4): 779-785.

Brenner H, Gefeller O, Hakulinen T (2004) Period analysis for 'up-to-date' cancer survival data: theory, empirical evaluation, computational realisation and applications. Eur J Cancer 40(3): 326-335.

Cancer Research UK Cancer Survival Group (2009) Life Tables for England by Sex, Calendar Period, Region and Deprivation. London School of Hygiene \& Tropical Medicine.

Coleman MP, Forman D, Bryant H, Butler J, Rachet B, Maringe C, Nur U, Tracey E, Coory M, Hatcher J, McGahan CE, Turner D, Marrett L, Gjerstorff ML, Johannesen TB, Adolfsson J, Lambe M, Lawrence G, Meechan D, Morris EJ, Middleton R, Steward J, Richards MA (2011) Cancer survival in Australia, Canada, Denmark, Norway, Sweden, and the UK, 1995-2007 (the International Cancer Benchmarking Partnership): an analysis of population-based cancer registry data. Lancet 377(9760): $127-138$.

Commission for Health Improvement (2001) National Service Framework Assessments No. 1Commission for Health Improvement: London.

Communities and Local Government (2007) Using the English Indices of Deprivation 2007: Guidance. Communities and Local Government: London.

Department of Health (2000) The NHS Cancer Plan. Department of Health: London.

Department of Health (2005) A Practical Guide to Ethnic Monitoring in the NHS and Social Care. Department of Health: London.

Department of Health (2008) DSCN 20/2008: Department of Health.

Dickman PW, Sloggett A, Hills M, Hakulinen T (2004) Regression models for relative survival. Stat Med 23(1): 51-64.

dos Santos Silva I, Mangtani P, De Stavola BL, Bell J, Quinn M, Mayer D (2003) Survival from breast cancer among South Asian and non-South Asian women resident in South East England. Br J Cancer 89(3): 508-512.

Ederer F, Axtell LM, Cutler SJ (1961) The relative survival rate: a statistical methodology. Natl Cancer Inst Monogr 6: 101-121.

Expert Advisory Group on Cancer (1995) A policy framework for commissioning cancer services: a report to the Chief Medical Officers of England and Wales. (The Calman-Hine Report). Department of Health: London.

Hospital Episode Statistics (2009) How Good Is HES Ethnic Coding and Where Do the Problems Lie? The Health and Social Care Information Centre: London.

Lavelle K, Todd C, Moran A, Howell A, Bundred N, Campbell M (2007) Non-standard management of breast cancer increases with age in the UK: a population based cohort of women $>$ or $=65$ years. Br J Cancer $96(8)$ : 1197-1203.

Lyratzopoulos G, Barbiere JM, Rachet B, Baum M, Thompson MR, Coleman MP (2011) Changes over time in socioeconomic inequalities in breast and rectal cancer survival in England and Wales during a 32-year period (1973-2004): the potential role of health care. Ann Oncol 22(7): $1661-1666$.

National Collaborating Centre for Cancer (2009) Early and Locally Advanced Breast Cancer: Diagnosis and Treatment. National Collaborating Centre for Cancer: Cardiff. 
NHS Connecting for Health (2009) OPCS Classification of Interventions and Procedures. Version 4.5TSO: London.

NHS Improvement (2008) Ensuring Better Treatment: Going Further on Cancer Waits. NHS Improvement: Leicester.

Noble M, mcLennan D, Wilkinson K, Whitworth A, Barnes H, Dibben C (2008) The English Indices of Deprivation 2007. Communities and Local Government: London.

Nur U, Shack LG, Rachet B, Carpenter JR, Coleman MP (2010) Modelling relative survival in the presence of incomplete data: a tutorial. Int $J$ Epidemiol 39(1): 118-128.

Office of National Statistics (2011) Cancer Registrations in England - 2010.

Potter S, Govindarajulu S, Shere M, Braddon F, Curran G, Greenwood R, Sahu AK, Cawthorn SJ (2007) Referral patterns, cancer diagnoses, and waiting times after introduction of two week wait rule for breast cancer: prospective cohort study. BMJ 335(7614): 288.

Rachet B, Ellis L, Maringe C, Chu T, Nur U, Quaresma M, Shah A, Walters S, Woods L, Forman D, Coleman MP (2010) Socioeconomic inequalities in cancer survival in England after the NHS cancer plan. Br J Cancer 103(4): 446-453.

Raine R, Wong W, Scholes S, Ashton C, Obichere A, Ambler G (2010) Social variations in access to hospital care for patients with colorectal, breast, and lung cancer between 1999 and 2006: retrospective analysis of hospital episode statistics. BMJ 340: b5479.

Richards MA, Smith P, Ramirez AJ, Fentiman IS, Rubens RD (1999) The influence on survival of delay in the presentation and treatment of symptomatic breast cancer. Br J Cancer 79(5-6): 858-864.

Ring A, Harder H, Langridge C, Ballinger RS, Fallowfield LJ (2013) Adjuvant chemotherapy in elderly women with breast cancer (AChEW): an observational study identifying MDT perceptions and barriers to decision making. Ann Oncol 24(5): 1211-1219.

Robinson D, Bell CM, Møller H, Basnett I (2003) Effect of the UK government's 2-week target on waiting times in women with breast cancer in southeast England. Br J Cancer 89(3): 492-496.

Royston P (2005) Multiple imputation of missing values: update of ice. Stata J 5: 527-536.

Rutherford MJ, Hinchliffe S, Abel G, Lyratzopoulos G, Lambert P, Greenberg D (2013) How much of the deprivation gap in cancer survival can be explained by variation in stage at diagnosis: an example from breast cancer in the East of England. Int J Cancer; e-pub ahead of print 18 April 2013; doi: $10.1002 /$ ijc.28221.

Sant M, Allemani C, Capocaccia R, Hakulinen T, Aareleid T, Coebergh JW, Coleman MP, Grosclaude P, Martinez C, Bell J, Youngson J, Berrino F, Group EW (2003) Stage at diagnosis is a key explanation of differences in breast cancer survival across Europe. Int J Cancer 106(3): $416-422$.

StataCorp (2011) Stata Statistical Software: Release 12. College Station, TX: StataCorp LP.

Sterne JA, White IR, Carlin JB, Spratt M, Royston P, Kenward MG, Wood AM, Carpenter JR (2009) Multiple imputation for missing data in epidemiological and clinical research: potential and pitfalls. $B M J$ 338: b2393.

Tavassoli F, Devilee P (eds) (2003) Pathology and Genetics of Tumours of the Breast and Female Genital Organs. IARC: Lyon.

Walters S, Maringe C, Butler J, Rachet B, Barrett-Lee P, Bergh J, Boyages J, Christiansen P, Lee M, Warnberg F, Allemani C, Engholm G, Fornander T, Gjerstorff ML, Johannesen TB, Lawrence G, McGahan CE, Middleton R, Steward J, Tracey E, Turner D, Richards MA, Coleman MP (2013) Breast cancer survival and stage at diagnosis in Australia, Canada, Denmark, Norway, Sweden and the UK, 2000-2007: a population-based study. Br J Cancer 108(5): 1195-1208.

Walters S, Quaresma M, Coleman MP, Gordon E, Forman D, Rachet B (2011) Geographical variation in cancer survival in England, 1991-2006: an analysis by Cancer Network. J Epidemiol Commun Health 65(11): 1044-1052.

Williams MV, Drinkwater KJ (2009) Geographical variation in radiotherapy services across the UK in 2007 and the effect of deprivation. Clin Oncol (R Coll Radiol) 21(6): 431-440.

This work is published under the standard license to publish agreement. After 12 months the work will become freely available and the license terms will switch to a Creative Commons AttributionNonCommercial-Share Alike 3.0 Unported License. 